\title{
S UMARIO
}

\section{INTRODUCCION}

Alberto BLASI, Un tema y una contribución $\ldots \ldots \ldots \ldots \ldots$

\section{ESTUDIOS}

Jaime Alazraki, Tres formas del ensayo contemporáneo: Borges, Paz, $\begin{array}{llllllllllllllllllll}\text { Cortázar } & \ldots & \ldots & \ldots & \ldots & \ldots & \ldots & \ldots & \ldots & \ldots & \ldots & \ldots & \ldots & \ldots & \ldots & \ldots & \ldots & \ldots & \ldots & \ldots\end{array}$

AlBerto Blasi, Vanguardismo en el Rio de la Plata: un «Diario» y una

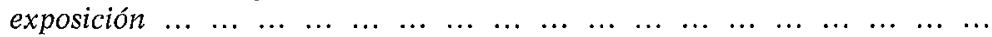

MANUEL DURÁN, «Contemporáneos»: ¿Grupo, promoción, generación, cons-

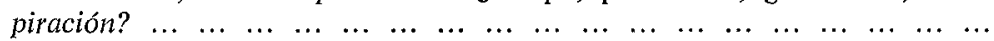

Peter G. Earle, El ensayo hispanoamericano, del Modernismo a la Mo$\begin{array}{llllllllllllllllllllll}\text { dernidad } & \ldots & \ldots & \ldots & \ldots & \ldots & \ldots & \ldots & \ldots & \ldots & \ldots & \ldots & \ldots & \ldots & \ldots & \ldots & \ldots & \ldots & \ldots & \ldots\end{array}$

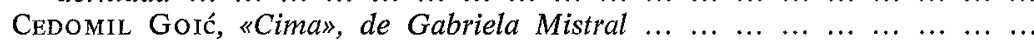

Roberto GonzÁlez EchevarRía, El primer relato de Severo Sarduy ... Jacoues Joset, El imposible «boom» de José Donoso $\ldots \ldots \ldots \ldots \ldots$ Bella Jozef, Modernismo brasileiro: Vanguarda, carnavalização e moder$\begin{array}{llllllllllllllllllll}\text { nidade } & \ldots & \ldots & \ldots & \ldots & \ldots & \ldots & \ldots & \ldots & \ldots & \ldots & \ldots & \ldots & \ldots & \ldots & \ldots & \ldots & \ldots & \ldots & \ldots \\ 103\end{array}$

Luis Leal, Agustín Yáñez y la novela mexicana. Rescate de una teoría ... 121

Walter Mignolo, La figura del poeta en la lírica de vanguardia ......... 131

Klaus Müller-Bergi, El hombre y la técnica: contribución al conocimiento de corrientes vanguardistas hispanoamericanas $\ldots$. .

RoBERTo PAOLI, «Los rios profundos»: la memoria y lo imaginario ... ...

Allen W. Phillips, Juan Ramón Jiménez e Hispanoamérica: su presencia

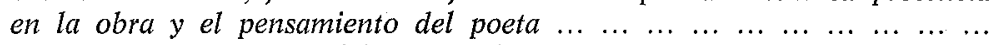

Leo Pollmann, Función del cuento latinoamericano $\ldots \begin{array}{lllll}\ldots & \ldots & \ldots & \ldots & \ldots\end{array}$

Robert Pring-Mill, Acciones paralelas y montaje acelerado en el segundo

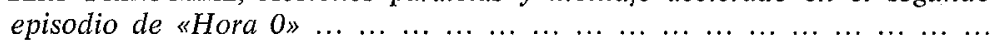

Hugo Rodríguez Alcalá, El vanguardismo en el Paraguay ... $\ldots . . . . .$.

EMIR Rodríguez MONEgAL, El olvidado ultraísmo uruguayo $\ldots \ldots \ldots \ldots$ 
Gustav Siebenmann, Ernesto Sábato y su postulado de una novela meta$\begin{array}{llllllllllllllllllllll}\text { fisica } & \ldots & \ldots & \ldots & \ldots & \ldots & \ldots & \ldots & \ldots & \ldots & \ldots & \ldots & \ldots & \ldots & \ldots & \ldots & \ldots & \ldots & \ldots & \ldots & \ldots\end{array}$

Hugo J. Verani, Una experiencia de limites: la narrativa de Cristina Peri $\begin{array}{lllllllllllllllllllll}R o s s i & \ldots & \ldots & \ldots & \ldots & \ldots & \ldots & \ldots & \ldots & \ldots & \ldots & \ldots & \ldots & \ldots & \ldots & \ldots & \ldots & \ldots & \ldots & \ldots & \ldots\end{array}$

Paul Verdevoye, Las novelas de Alejo Carpentier y la realidad maravillosa.

Gloria Videla de Rivero, Poesía de vanguardia en Iberoamérica a través de la revista «La Pluma», de Montevideo (1927-1931) ... . . ... . . ...

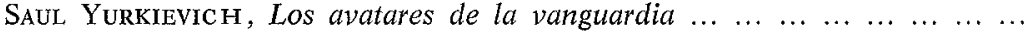

\section{NOTAS}

Enrique Anderson Imbert, Alejandro Korn y el positivismo ... $\ldots \ldots \ldots$

Ana María Barrenechea, la crisis del contrato mimético en los textos

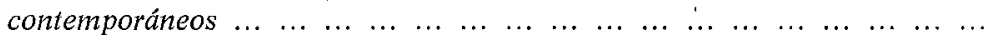

Paul W. Borgeson, Lenguaje hablado/lenguaje poético: Parra, Cardenal

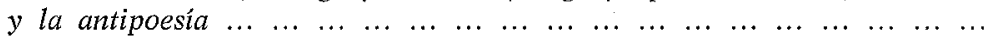

Merlin H. Forster, Nota sobre algunos primeros poemas de Vicente Hui-

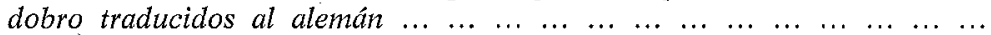

MARGo Glantz, Fantasmas y jardines: una familia lejana $\ldots . . . \ldots \ldots \ldots$

StePhanie MERrim, «La Habana para un infante difunto» y su teoría

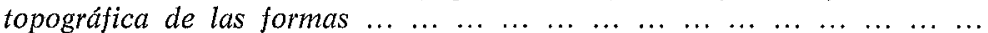

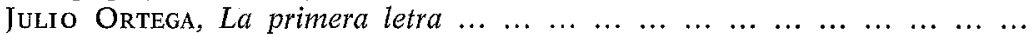

\section{RESEÑAS}

EFraín BARRADAS, sobre Manuel Ramos Otero, El cuento de la mujer

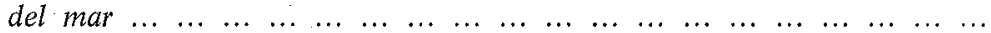

Rei BerroA, sobre José Alcántara Almánzar, Estudios de poesía dominicana.

Pedro Bravo-Ellzondo, sobre Gabriela Mistral ... $\ldots \ldots \ldots \ldots \ldots$

Marcelo CoDDou, sobre David Turkeltab, Ganymedes/6: Una panorámica

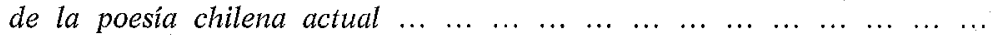

RAQUel CHANG-Rodríguez, sobre Lucía Fox-Lockert, Women Novelists in

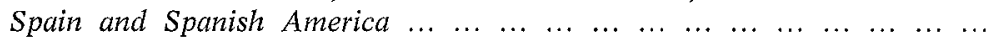

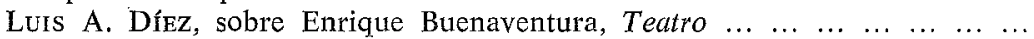

Evelto Echevarría, sobre César Vallejo, Teatro completo ... ... ... ......

Lucía Fox-Lockert, sobre Nora Jacquez Wieser, Open to the Sun ... ...

SÉrgio FrançA DANESE, sobre Irlemar Chiampi, O realismo maravilhoso.

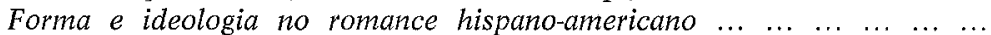

DoNald McGrady, sobre José Asunción Silva, Intimidades ... ... ... . . . ...

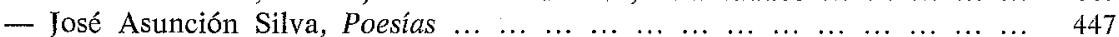

- Betty Tyree Osiek, José Asunción Silva $\ldots \ldots \ldots \ldots \ldots \ldots \ldots$

Perla Rosencvaig, sobre Reinaldo Arenas, El palacio de las blanquísimas $\begin{array}{lllllllllllllllllllll}\operatorname{mofetas} & \ldots & \ldots & \ldots & \ldots & \ldots & \ldots & \ldots & \ldots & \ldots & \ldots & \ldots & \ldots & \ldots & \ldots & \ldots & \ldots & \ldots & \ldots & \ldots\end{array}$

Armando Zárate, sobre Juan Coletti, El jardín de las flores invisibles ... 